\title{
Postpartum Uterine Inversion
}

National Cancer Institute

\section{Source}

National Cancer Institute. Postpartum Uterine Inversion. NCI Thesaurus. Code C114377.

Protrusion of the uterine fundus through the cervix when the placenta fails to detach from the uterus as it exits. 